\title{
Right ventricular dysfunction as an echocardiographic prognostic factor in hemodynamically stable patients with acute pulmonary embolism: a meta-analysis
}

Jae Hyung Cho ${ }^{1 *}$, Gurusaravanan Kutti Sridharan ${ }^{2}$, Seon Ha Kim ${ }^{3}$, Roop Kaw ${ }^{4}$, Triveni Abburi', Affan Irfan ${ }^{2}$ and Abraham G Kocheril ${ }^{5}$

\begin{abstract}
Background: We investigated whether right ventricular dysfunction (RVD) as assessed by echocardiogram can be used as a prognostic factor in hemodynamically stable patients with acute pulmonary embolism (PE). Short-term mortality has been investigated only in small studies and the results have been controversial.

Methods: A PubMed search was conducted using two keywords, "pulmonary embolism" and "echocardiogram", for articles published between January 1st 1998 and December 31st 2011. Out of 991 articles, after careful review, we found 12 articles that investigated the implications of RVD as assessed by echocardiogram in predicting short-term mortality for hemodynamically stable patients with acute PE. We conducted a meta-analysis of these data to identify whether the presence of RVD increased short-term mortality.

Results: Among 3283 hemodynamically stable patients with acute PE, 1223 patients (37.3\%) had RVD, as assessed by echocardiogram, while 2060 patients (62.7\%) had normal right ventricular function. Short-term mortality was reported in 167 (13.7\%) out of 1223 patients with RVD and in 134 (6.5\%) out of 2060 patients without RVD. Hemodynamically stable patients with acute PE who had RVD as assessed by echocardiogram had a 2.29-fold increase in short-term mortality (odds ratio 2.29, 95\% confidence interval 1.61-3.26) compared with patients without RVD.

Conclusions: In hemodynamically stable patients with acute PE, RVD as assessed by echocardiogram increases short-term mortality by 2.29 times. Consideration should be given to obtaining echocardiogram to identify high-risk patients even if they are hemodynamically stable.
\end{abstract}

Keywords: Echocardiography, Pulmonary embolism, Right ventricular dysfunction

\section{Background}

Acute pulmonary embolism (PE), commonly originating from deep venous thrombosis (DVT), is a potentially life-threatening condition. PE incidence is approximately 69 per 100,000 according to a 25-year population-based study [1]. PE can be broadly classified as either massive or submassive. Patients with massive PE usually present with hemodynamic instability and are treated with either

\footnotetext{
*Correspondence: choj2@ccf.org

'Department of Hospital Medicine, Cleveland Clinic, OH, 9500 Euclid Avenue, M2-Annex, Cleveland, OH 44195, USA

Full list of author information is available at the end of the article
}

thrombolytic therapy or pulmonary embolectomy, while patients with submassive PE are generally hemodynamically stable and can be treated with anticoagulation alone. Recent evidence suggests that in selected low-risk patients with acute PE, outpatient care can be as safe and effective as inpatient care [2].

Untreated PE patients reportedly have a 30\% mortality rate, whereas treated $\mathrm{PE}$ patients have an $8 \%$ mortality rate [3]. PE can cause right ventricular dilatation and dysfunction because of increased right ventricular afterload, leading to right ventricular failure and subsequently death. Echocardiogram is essential in ruling out intracardiac 
thrombus and has been widely used to assess right ventricular dysfunction (RVD). Few studies have investigated the prognostic implications of RVD as assessed by echocardiogram in hemodynamically stable patients with acute PE and the results have been controversial. There have been two previous meta-analyses regarding the assessment of RVD by echocardiogram in hemodynamically stable patients with acute PE that revealed increased short-term mortality $[4,5]$. However, the clinical impact of RVD as assessed by echocardiogram is still controversial and current venous thromboembolism guidelines do not recommend the routine echocardiogram to assess right ventricular function in hemodynamically stable patients with acute PE [6]. Hence, we conducted a new metaanalysis to examine the implication of RVD as assessed by echocardiogram in hemodynamically stable patients with acute PE.

\section{Methods}

\section{Study objective}

Few studies have studied whether RVD as assessed by echocardiogram increases short-term mortality (inhospital or 30-day mortality) in hemodynamically stable patients with acute PE, which is controversial. The objective of this meta-analysis is to assess the prognostic value of RVD determination on echocardiogram in hemodynamically stable patients with acute PE. We followed the PRISMA statements for reporting meta-analyses.

\section{Study outcome}

The study outcome of our meta-analysis was short-term mortality, which included in-hospital and 30-day mortality. Studies that investigated adverse clinical events such as intubation, cardiopulmonary resuscitation or the use of vasopressors, were excluded. Studies with 14-day, 3-month or 6-month mortality were also excluded to decrease meta-analysis heterogeneity.

\section{Search strategy}

We searched PubMed using two keywords, "pulmonary embolism" and "echocardiogram". Search criteria included the time frame between January 1st 1998 and December 31th 2011, humans, English, and adults older than 19 years. A total of 991 articles were included in our initial search. The articles were independently reviewed by two authors (J.H.C. and G.K.S.). The initial screening was performed by first reviewing the titles and the abstracts were reviewed if they contained text describing the prognostic value of RVD assessment. After reviewing the titles and abstracts, 106 articles were selected for full review. In total, eighteen out of 106 studies investigated the implications of RVD as assessed by echocardiogram in hemodynamically stable patients with acute
PE. The rest of the eighty-eight studies were excluded for the following reasons: they were not investigational studies, they had different study objectives, they used different patient populations such as hemodynamically unstable PE or chronic PE, or they used different RVD diagnostic modalities such as CT, cardiac biomarkers or brain natriuretic peptide (BNP). In total, six studies had different clinical outcomes such as 14-day, 40-day, 3 -month mortality or adverse clinical outcomes, which were excluded. Finally, twelve studies were selected for our meta-analysis (Figure 1). The disagreements between these two authors were reviewed and the two disagreeing studies were excluded because of different clinical outcomes. After meticulous review, the data were extracted independently by the two aforementioned authors using standard data extraction forms and were confirmed together.

\section{Eligibility criteria}

We used studies that included only hemodynamically stable patients with acute PE. We excluded hemodynamically unstable patients with acute PE. Hemodynamic instability was defined as systolic blood pressure less than $90 \mathrm{mmHg}$ or a systolic blood pressure drop greater than $40 \mathrm{mmHg}$ from the baseline. We also excluded patients with chronic PE. We selected studies that investigated the implications of RVD assessment by echocardiogram to predict shortterm mortality, which includes in-hospital or 30-day mortality. RVD can be assessed by echocardiogram, CT, cardiac biomarkers or BNP. However, we only included studies that investigated RVD using echocardiogram. We excluded studies that focused on mortality other than in-hospital or 30-day. We excluded studies that investigated adverse clinical outcomes such as intubation, cardiopulmonary resuscitation or vasopressor use.

\section{Statistical analysis}

We performed meta-analysis using RevMan 5.0 with the Mantel-Haenszel random effects model. Cochran's chi-square test and the $\mathrm{I}^{2}$ test were used to assess between-study heterogeneity. Heterogeneity was considered statistically significant at $\mathrm{P}<0.10$ and $\mathrm{I}^{2}>50 \%$. Pooled odds ratios were reported with $95 \%$ confidence intervals.

\section{Subgroup analyses}

Subgroup analyses were performed according to the outcome measure (in-hospital mortality vs. 30-day mortality) and the study design (prospective vs. retrospective).

\section{Results}

Study selection

A total of 991 articles were included in our initial search. After a thorough review of titles and abstracts, 106 journals 


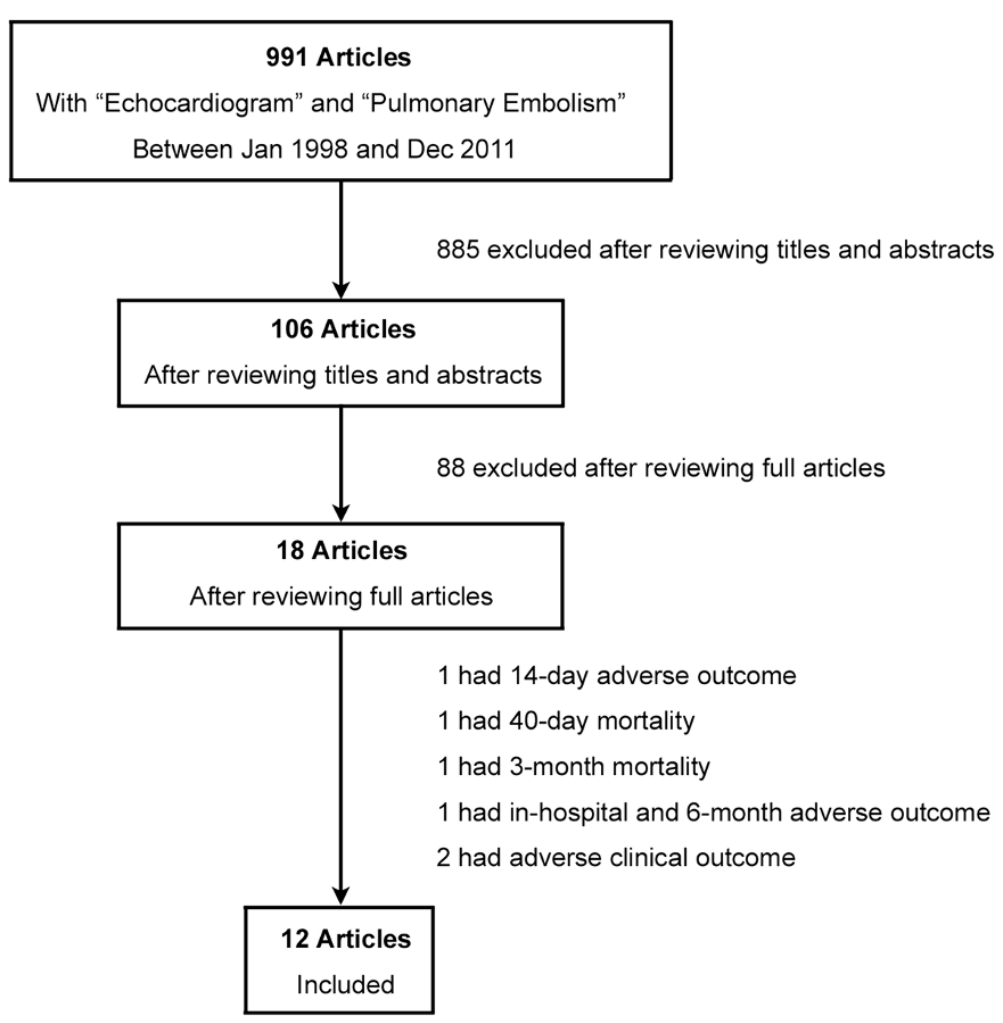

Figure 1 Study selection.

were selected as preliminary candidates. After reviewing full articles, 12 studies $(n=3283)$ were selected for data extraction and meta-analysis.

\section{Study characteristics}

A total of 3283 patients were included in our metaanalysis. Individual characteristics of the included studies are shown in Table 1 . As a study outcome, nine studies measured in-hospital mortality while three studies investigated 30-day mortality. In total, seven studies were prospective whereas five studies were retrospective. The qualitative findings of included studies using NewcastleOttawa quality assessment scale are described in Table 2 .

Right ventricular dysfunction as assessed by echocardiogram The American Society of Echocardiography published "Guidelines for the Echocardiographic Assessment of the Right Heart in Adults" in 2010 [19]. However, because most of our studies were performed before this guideline was published, the definition of RVD as assessed by echocardiogram differed from study to study. The echocardiographic criteria of RVD in each study are described in Table 1 . The most commonly used criteria were: right ventricular end-diastolic diameter $>30 \mathrm{~mm}$, right ventricular/left ventricular end-diastolic diameter $>1$ or right ventricular hypokinesia. Other criteria included paradoxical septal wall motion, pulmonary hypertension and severe tricuspid regurgitation.

\section{Right ventricular dysfunction predicting in-hospital or 30-day mortality}

Among 3283 hemodynamically stable patients with acute PE, 1223 patients (37.3\%) had RVD as assessed by echocardiogram while 2060 patients (62.7\%) had normal right ventricular function. Short-term mortality was reported in 167 (13.7\%) out of 1223 patients with RVD and in 134 (6.5\%) out of 2060 patients without RVD. Hemodynamically stable patients with acute PE who had RVD as assessed by echocardiogram had a 2.29-fold increase in short-term mortality (Figure 2) (odds ratio (OR) 2.29, 95\% confidence interval (CI) 1.61-3.26) compared with patients without RVD.

\section{Subgroup analyses}

Subgroup analyses demonstrated that patients with RVD as assessed by echocardiogram had a 2.60 -fold increase in in-hospital mortality (Figure 3 ) and a 1.98-fold increase in 30-day mortality (Figure 4) (OR 2.60, 95\% CI 1.43-4.72, and OR 1.98, 95\% CI 1.43-2.73, respectively). Prospective study subgroup analysis revealed that patients with RVD as assessed by echocardiogram had a 1.61-fold increase in short-term mortality (Figure 5) while retrospective studies demonstrated a 2.92 -fold increase in short-term mortality 
Table 1 Study characteristics

\begin{tabular}{|c|c|c|c|c|c|c|c|c|c|c|c|}
\hline & \multirow{2}{*}{$\begin{array}{l}\text { Author } \\
\text { (Journal) }\end{array}$} & \multirow[t]{2}{*}{ Year } & \multirow{2}{*}{$\begin{array}{l}\text { Study } \\
\text { design }\end{array}$} & \multirow{2}{*}{$\begin{array}{l}\text { Patients } \\
\text { number }\end{array}$} & \multirow[t]{2}{*}{ Diagnostic nodality } & \multirow[t]{2}{*}{ RVD Definition } & \multirow[t]{2}{*}{ Follow-up } & \multicolumn{2}{|c|}{ RVD (+) } & \multicolumn{2}{|c|}{ RVD (-) } \\
\hline & & & & & & & & Death & Total & Death & Total \\
\hline 1 & $\begin{array}{l}\text { Grifoni et al. [7] } \\
\text { (Circulation) }\end{array}$ & 2000 & Prospective & 162 & $\begin{array}{c}\mathrm{CT}, \mathrm{V} / \mathrm{Q} \text { scan or pulmonary } \\
\text { angiography }\end{array}$ & $\begin{array}{c}\text { RVEDD }>30 \mathrm{~mm}, \mathrm{RV} / \mathrm{LV}>1, \\
\text { PSWM, or PH }\end{array}$ & In-hospital mortality & 4 & 65 & 3 & 97 \\
\hline 2 & $\begin{array}{l}\text { Yalamanchili et al. [8] } \\
\qquad \text { (Am J Cardiol) }\end{array}$ & 2004 & Retrospective & 91 & CT & $\begin{array}{l}\text { RVEDD }>30 \mathrm{~mm} \text {, or } \\
\text { RVHK and PSWM }\end{array}$ & In-hospital mortality & 4 & 25 & 8 & 66 \\
\hline 3 & $\begin{array}{l}\text { Kucher et al. [9] } \\
\text { (Arch Intern Med) }\end{array}$ & 2005 & Retrospective & 1035 & $\begin{array}{c}\text { Necropsy, V/Q scan, pulmonary } \\
\text { angiography or high suspicion in } \\
\text { the setting of DVT }\end{array}$ & RVHK & 30-day mortality & 65 & 405 & 59 & 630 \\
\hline 4 & $\begin{array}{l}\text { Sukhija et al. [10] } \\
\text { (Am J Cardiol) }\end{array}$ & 2005 & Retrospective & 190 & CT & $\begin{array}{l}\text { Right ventricular dilatation } \\
(\mathrm{RV}>\mathrm{LV} \text {, or } \mathrm{RV}>4.5 \mathrm{~cm})\end{array}$ & In-hospital mortality & 21 & 64 & 6 & 126 \\
\hline 5 & $\begin{array}{l}\text { Grifoni et al. [11] } \\
\text { (Arch Intern Med) }\end{array}$ & 2006 & Prospective & 301 & $\begin{array}{c}C T, V / Q \text { scan or pulmonary } \\
\text { angiography }\end{array}$ & $\begin{array}{c}\text { RVEDD }>30 \mathrm{~mm}, \mathrm{RV} / \mathrm{LV}>1, \\
\text { PSWM, or PH }\end{array}$ & In-hospital mortality & 24 & 146 & 21 & 155 \\
\hline 6 & $\begin{array}{l}\text { Pieralli et al. [12] } \\
\text { (Am J Cardiol) }\end{array}$ & 2006 & Prospective & 61 & CT or pulmonary angiography & $\begin{array}{l}\text { RVEDD }>30 \mathrm{~mm}, \mathrm{RV} / \mathrm{LV}>1, \\
\text { RVHK, PSWM, or PH }\end{array}$ & In-hospital mortality & 4 & 35 & 0 & 26 \\
\hline 7 & $\begin{array}{c}\text { Jimenez et al. [13] } \\
\text { (Arch Bronchoneumol) }\end{array}$ & 2007 & Prospective & 214 & CT or V/Q scan & RVEDD $>30 \mathrm{~mm}, \mathrm{RV}>\mathrm{LV}$, or RVHK & 30-day mortality & 4 & 86 & 3 & 128 \\
\hline 8 & $\begin{array}{l}\text { Logeart et al. [14] } \\
\text { (Intensive Care Med) }\end{array}$ & 2007 & Prospective & 67 & $\mathrm{CT}$ or $\mathrm{V} / \mathrm{Q}$ scan & $\begin{array}{l}\text { Two or more of RV/LV>0.7, } \\
\text { RVHK, IVC }>10 \mathrm{~mm} \text { during inspiration, } \\
\text { IVC bulging, TRV }>2.7 \mathrm{~m} / \mathrm{s}\end{array}$ & In-hospital mortality & 1 & 36 & 0 & 31 \\
\hline 9 & $\begin{array}{l}\text { Palmieri et al. [15] } \\
\text { (Intern Emerg Med) }\end{array}$ & 2008 & Prospective & 89 & CT & $\begin{array}{l}\text { RV/LV }>0.9 \text {, PSWM, or depressed } \\
\text { RV systolic function }\end{array}$ & In-hospital mortality & 8 & 48 & 4 & 41 \\
\hline 10 & $\begin{array}{l}\text { Gallotta et al. [16] } \\
\text { (Int J Cardio) }\end{array}$ & 2008 & Prospective & 90 & CT & $\begin{array}{l}\text { PSWM, RV diameter }>15 \mathrm{~mm} / \mathrm{m}^{2} \text {, } \\
\text { or low RV systolic function }\end{array}$ & In-hospital mortality & 10 & 65 & 2 & 25 \\
\hline 11 & $\begin{array}{l}\text { Stein et al. [17] } \\
\text { (Am J Cardio) }\end{array}$ & 2011 & Retrospective & 392 & $\mathrm{CT}$ or V/Q scan & $\begin{array}{l}\text { Quantitative in } 325 \text { patients, } \\
\text { or RV/LV }>1 \text { in } 67 \text { patients }\end{array}$ & In-hospital mortality & 4 & 264 & 8 & 128 \\
\hline 12 & $\begin{array}{l}\text { Jimenez et al. [18] } \\
\text { (Thorax) }\end{array}$ & 2011 & Retrospective & 591 & $\begin{array}{c}C T, V / Q \text { scan or high suspicion } \\
\text { in the setting of DVT }\end{array}$ & $\begin{aligned} & \text { RVEDD }>30 \mathrm{~mm}, \mathrm{RV}>\mathrm{LV}, \mathrm{RVHK}, \\
& \text { or } T R V>2.6 \mathrm{~m} / \mathrm{s}\end{aligned}$ & 30-day mortality & 14 & 120 & 24 & 471 \\
\hline
\end{tabular}

RVEDD (Right ventricular end-diastolic diameter in precordial view), RV/LV (Right ventricular/left ventricular end-diastolic diameter in 4-chamber view), PSWM (Paradoxical septal wall motion), PH (Pulmonary hypertension), RVHK (Right ventricular hypokinesia), IVC (Inferior vena cava), TRV (Tricuspid regurgitation velocity). 
Table 2 Qualitative findings (Newcastle-Ottawa Quality Assessment Scale)

\begin{tabular}{|c|c|c|c|c|c|c|c|c|c|c|}
\hline & \multirow[b]{2}{*}{$\begin{array}{l}\text { Author } \\
\text { (Journal) }\end{array}$} & \multicolumn{4}{|c|}{ Selection } & \multirow{2}{*}{$\begin{array}{c}\text { Comparability } \\
\text { Comparability of cases } \\
\text { and controls (age) }\end{array}$} & \multicolumn{3}{|c|}{ Exposure } & \multirow[b]{2}{*}{ Total score } \\
\hline & & $\begin{array}{c}\text { Is the case } \\
\text { definition adequate? }\end{array}$ & $\begin{array}{l}\text { Representativeness } \\
\text { of the cases }\end{array}$ & $\begin{array}{l}\text { Selection } \\
\text { of controls }\end{array}$ & $\begin{array}{l}\text { Definition } \\
\text { of controls }\end{array}$ & & $\begin{array}{l}\text { Ascertainment } \\
\text { of exposure }\end{array}$ & $\begin{array}{l}\text { Same method of } \\
\text { ascertainment of } \\
\text { cases and controls }\end{array}$ & $\begin{array}{c}\text { Non-response } \\
\text { rate }\end{array}$ & \\
\hline 1 & $\begin{array}{l}\text { Grifoni et al. [7] } \\
\text { (Circulation) }\end{array}$ & 1 & 1 & 1 & 1 & 1 & 1 & 1 & 1 & 8 \\
\hline 2 & $\begin{array}{l}\text { Yalamanchili et al. [8] } \\
\text { (Am J Cardiol) }\end{array}$ & 1 & 1 & 1 & 1 & 0 & 1 & 1 & 1 & 7 \\
\hline 3 & $\begin{array}{l}\text { Kucher et al. [9] } \\
\text { (Arch Intern Med) }\end{array}$ & 0 & 1 & 1 & 1 & 1 & 1 & 1 & 1 & 7 \\
\hline 4 & $\begin{array}{l}\text { Sukhija et al. [10] } \\
\text { (Am J Cardiol) }\end{array}$ & 0 & 1 & 1 & 1 & 0 & 1 & 1 & 1 & 6 \\
\hline 5 & $\begin{array}{l}\text { Grifoni et al. [11] } \\
\text { (Arch Intern Med) }\end{array}$ & 1 & 1 & 1 & 1 & 1 & 1 & 1 & 1 & 8 \\
\hline 6 & $\begin{array}{l}\text { Pieralli et al. [12] } \\
\text { (Am J Cardiol) }\end{array}$ & 1 & 1 & 1 & 1 & 1 & 1 & 1 & 1 & 8 \\
\hline 7 & $\begin{array}{c}\text { Jimenez et al. [13] } \\
\text { (Arch Bronchoneumol) }\end{array}$ & 1 & 1 & 1 & 1 & 1 & 1 & 1 & 1 & 8 \\
\hline 8 & $\begin{array}{l}\text { Logeart et al. [14] } \\
\text { (Intensive Care Med) }\end{array}$ & 1 & 1 & 1 & 1 & 1 & 1 & 1 & 1 & 8 \\
\hline 9 & $\begin{array}{l}\text { Palmieri et al. [15] } \\
\text { (Intern Emerg Med) }\end{array}$ & 1 & 1 & 1 & 1 & 0 & 1 & 1 & 1 & 7 \\
\hline 10 & $\begin{array}{l}\text { Gallotta et al. [16] } \\
\text { (Int J Cardio) }\end{array}$ & 1 & 1 & 1 & 1 & 0 & 1 & 1 & 1 & 7 \\
\hline 11 & $\begin{array}{l}\text { Stein et al. [17] } \\
\text { (Am J Cardio) }\end{array}$ & 0 & 1 & 1 & 1 & 0 & 1 & 1 & 1 & 6 \\
\hline 12 & $\begin{array}{l}\text { Jimenez et al. [18] } \\
\text { (Thorax) }\end{array}$ & 1 & 1 & 1 & 1 & 1 & 1 & 1 & 1 & 8 \\
\hline
\end{tabular}




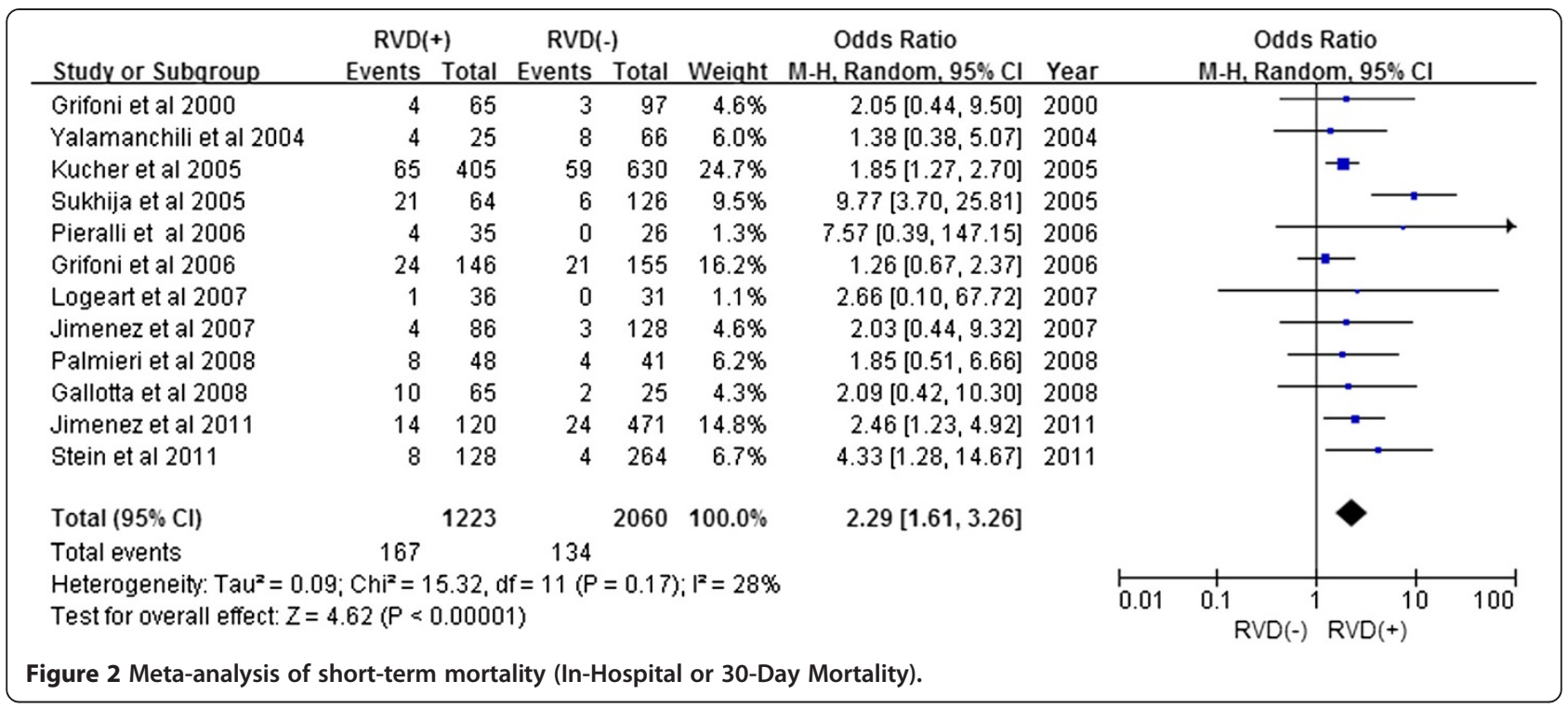

(Figure 6) (OR 1.61, 95\% CI 1.01-2.57, and OR 2.92, 95\% CI 1.58-5.42, respectively).

\section{Risk of bias}

To decrease the risk of bias, two authors independently assessed the validity of the included studies at the outcome level. To increase homogeneity, we only included studies with clinical outcomes of either in-hospital or 30-day mortality. There might be a publication bias despite meticulous database searches because small negative studies or positive studies without statistical significance might not get published. To minimize selection bias we used very clear inclusion and exclusion criteria.

\section{Discussion}

RVD has long been thought to be a cause of death in patients with acute PE. Right ventricular function can be assessed using echocardiogram, CT, cardiac biomarkers or BNP. Several studies investigated the implication of elevated cardiac biomarkers or BNP levels and concluded that patients with elevated levels have an increased mortality rate $[4,5,20]$. Because patients with congestive heart failure, chronic kidney disease, stroke or other pulmonary disease may also have elevated baseline cardiac biomarker or BNP levels, there are limitations to assess right ventricular function. However, an echocardiogram is more specific to assess right ventricular function because we can directly image the right ventricle with the echocardiogram, which is not influenced by other co-morbidities.

Recent studies suggest that certain patients with low-risk profiles can be managed safely at home without hospitalization [2]. High-risk profiles include old age, congestive heart failure, chronic lung disease,

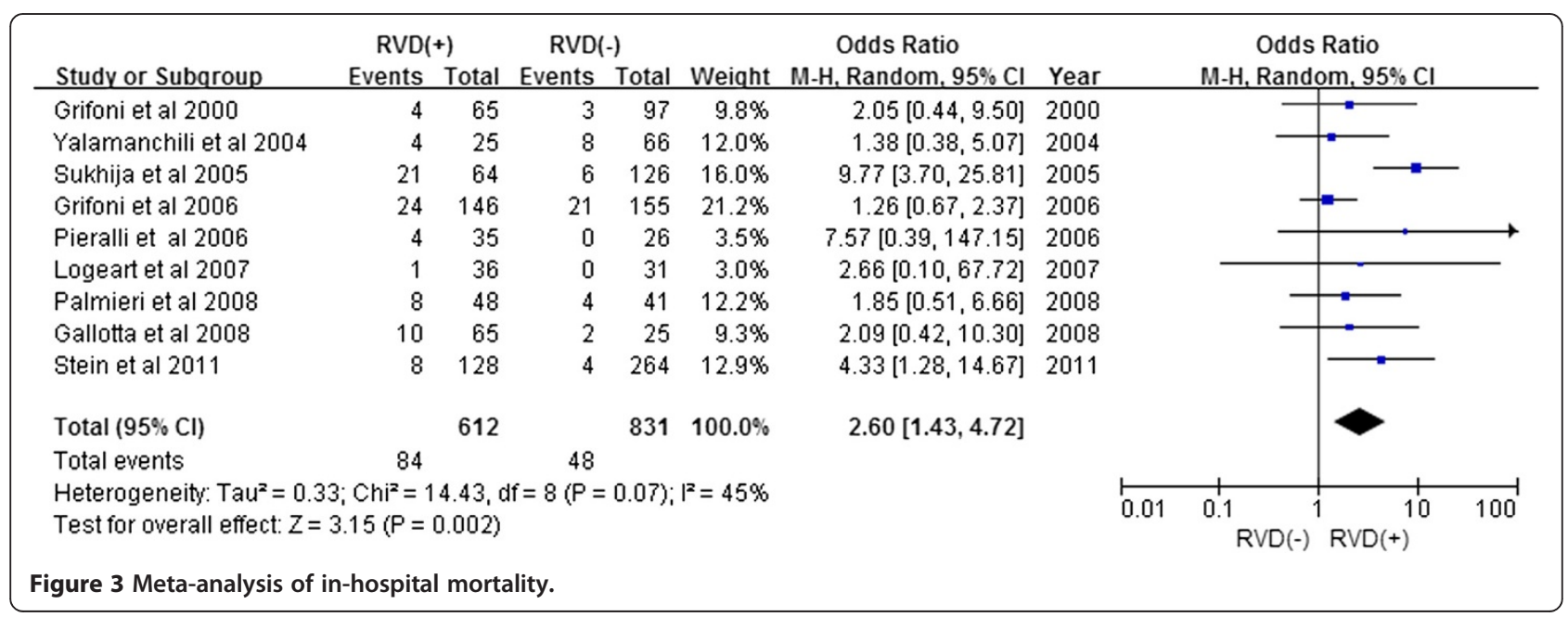




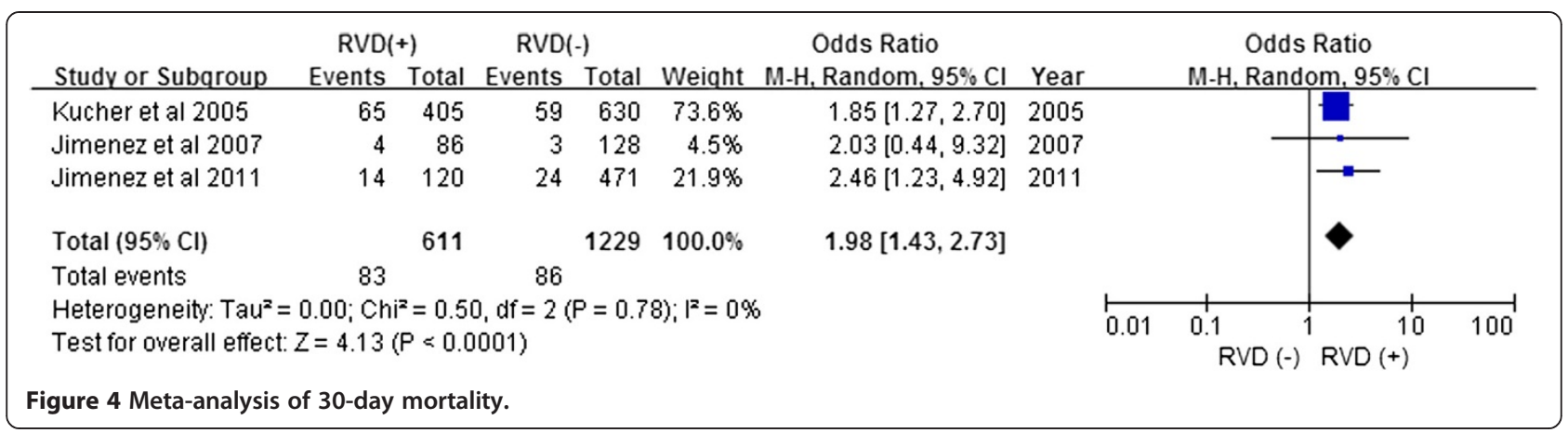

pulse $>110 \mathrm{bpm}$, systolic blood pressure $<100 \mathrm{mmHg}$, respiratory rate $>30$ breaths per min or arterial oxygen saturation $<90 \%$ according to the pulmonary embolism severity index [21,22]. Our meta-analysis indicated that patients with RVD as assessed by echocardiogram should be regarded as high-risk because RVD increases shortterm mortality. However, the current guidelines of venous thromboembolism do not recommend the routine use of cardiac biomarkers, BNP, CT or echocardiogram to assess right ventricular function in hemodynamically stable patients because it will not change patient management [6]. The positive predictive value of mortality on the basis of echocardiographic evidence of RVD in hemodynamically stable patients has generally been reported to be in the 5 to $8 \%$ range $[7,13]$. We suggest consideration be given to obtaining echocardiogram with special emphasis on right ventricular wall motion in normotensive patients with acute PE, especially when they have dyspnea, tachypnea or tachycardia.

The use of RVD as assessed by echocardiogram as a prognostic factor in acute PE has been controversial. As described in our included studies, eight out of twelve studies demonstrated non-significant results in predicting mortality $[7,8,11-16]$. Only four studies revealed a statistically significantly increased mortality rate $[9,10,17,18]$. There have been two previous metaanalyses regarding RVD assessment by echocardiogram. Sanchez et al. included five studies and Coutance et al. included eight studies $[4,5]$. However, the clinical outcome of these meta-analyses had wide variations from in-hospital mortality to $14-, 30-$ or 40 -day mortality $[4,5]$. Our meta-analysis included 12 studies with uniform clinical outcomes of either in-hospital or 30-day mortality. Short-term mortality, which includes in-hospital or 30-day mortality, was increased 2.29-fold in patients with RVD as assessed by echocardiogram. Subgroup analyses revealed that patients with RVD as assessed by echocardiogram have a 2.60 -fold increase in in-hospital mortality and a 1.98 -fold increase in 30-day mortality. None of these meta-analyses demonstrated significant heterogeneity. Although treatment of RVD without hemodynamic instability among patients with PE was not within the scope of our meta-analysis, several studies have addressed this issue [23-25]. The most recent study randomized patients with intermediate-risk PE (as defined by RVD on echocardiogram or spiral CT and myocardial injury as defined by troponin elevation) to thrombolytic agent (tenecteplase) vs. intravenous heparin [25]. Decreased composite of hemodynamic instability and death (2.6\%) but higher risk of hemorrhagic stroke $(2.0 \%)$ and major

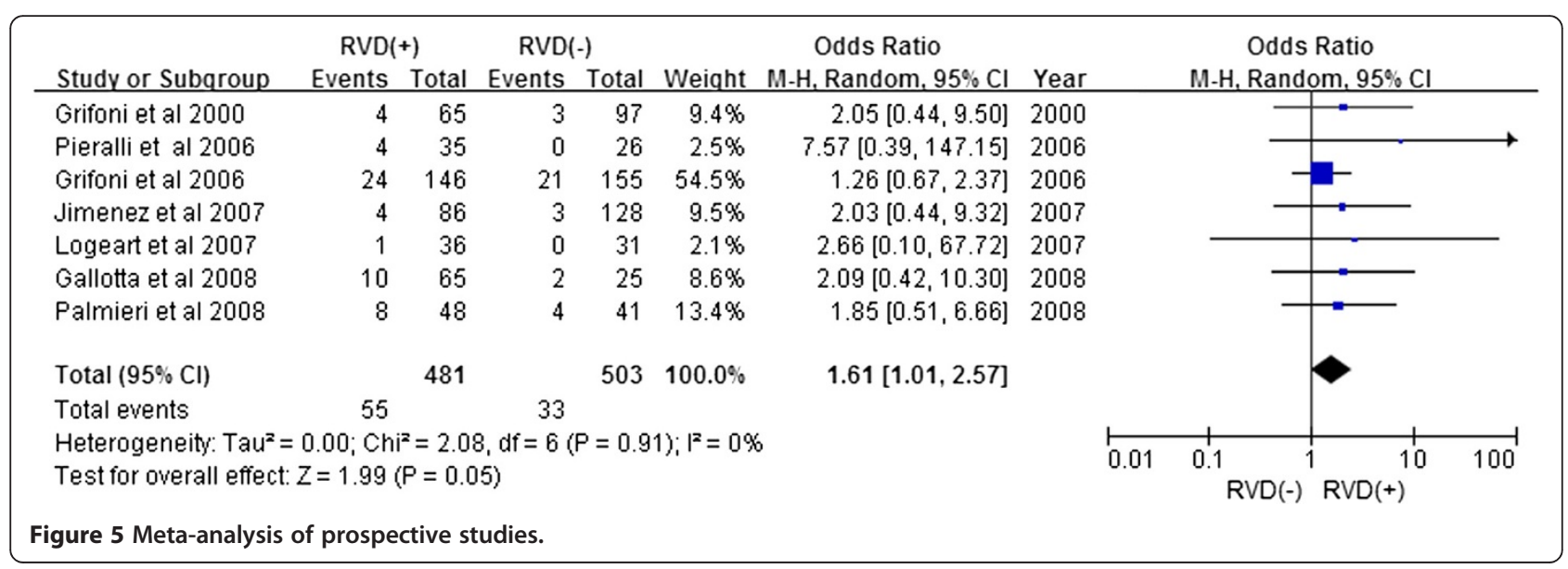




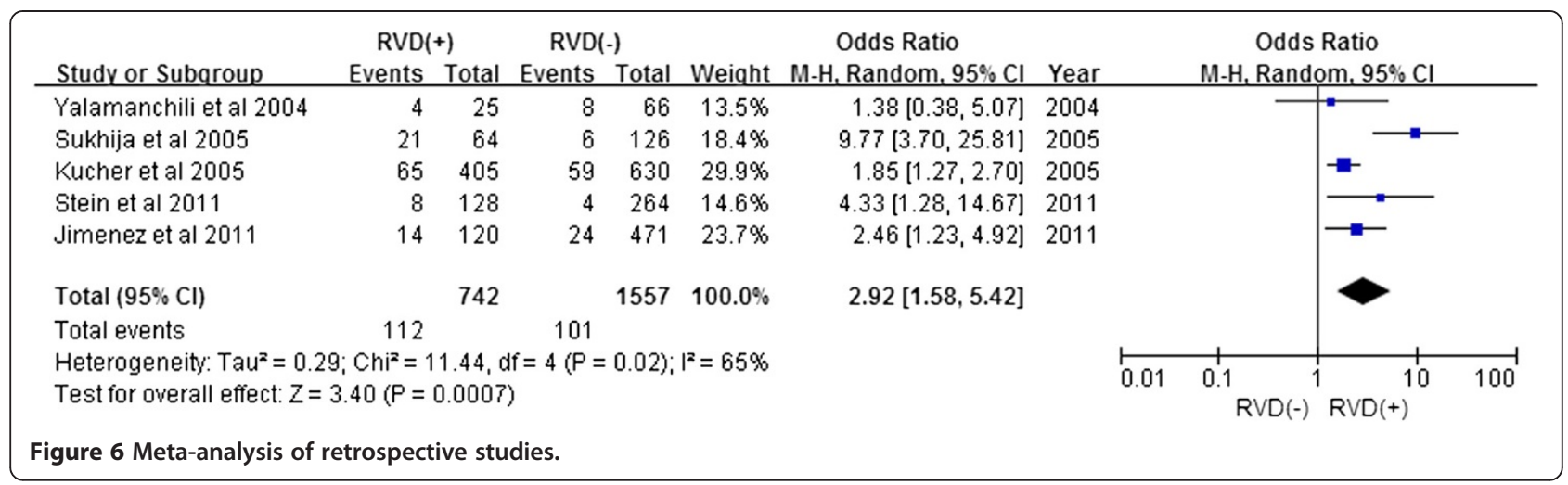

extracranial hemorrhage (6.3\%) were noted in the group treated with tenecteplase, thus advising cautious use of thrombolytic agent among hemodynamically stable patients with RVD [25].

There are several limitations to our meta-analysis. First, we used only one database for the study selection. PubMed is the major search engine for medical literature; however, we could increase the power of our meta-analysis by including other search engines such as Cochrane or Embase. Even using only with PubMed, we found significant studies with adequate homogeneity. Second, the definition of RVD as assessed by echocardiogram differed among the studies (Table 1). In particular, in the study by Sukhija et al. it is possible that too stringent criteria for RVD (RV $>\mathrm{LV}$, or $\mathrm{RV}>4.5 \mathrm{~cm}$ ) were used which may have contributed to a very high OR for short-term mortality [10]. In light of such high shortterm mortality, it is also possible that even though the patients in this study were classified as hemodynamically stable, some of them may really have had some clinical clue or deterioration which was missed. Although the American Society of Echocardiography published a guideline of assessing the right heart in an adult population in 2010, most of the studies were performed before the publication of this guideline [19]. In the future, the homogeneity can be increased and subgroup analysis of different echocardiographic RVD criteria can be performed if we have sufficient studies that followed this guideline. Third, it is hard to assess whether RVD is an acute finding secondary to PE or a chronic condition because of other co-morbidities because most of these patients do not have a baseline echocardiogram to check right ventricular function. Differentiation of acute versus chronic RVD would also be difficult solely on echocardiographic findings. Because it is not practical to obtain a baseline echocardiogram before PE development, this assessment will remain a future research area. Lastly, some studies in the metaanalysis lacked stringent exclusion criteria and it is possible that hemodynamic instability was under-reported.

\section{Conclusions}

In hemodynamically stable patients with acute PE, RVD as assessed by echocardiogram increases short-term mortality by 2.29 times. Consideration should be given to obtaining echocardiogram to identify high-risk patients even if they are hemodynamically stable.

\section{Abbreviations}

PE: Pulmonary embolism; DVT: Deep vein thrombosis; RVD: Right ventricular dysfunction; BNP: Brain natriuretic peptide; RVEDD: Right ventricular end-diastolic diameter in precordial view; RV/LV: Right ventricular/Left ventricular end-diastolic diameter in 4-chamber view; PSWM: Paradoxical septal wall motion; PH: pulmonary hypertension; RVHK: Right ventricular hypokinesia; IVC: Inferior vena cava; TRV: Tricuspid regurgitation velocity; OR: Odds ratio; Cl: Confidence interval.

\section{Competing interests}

The authors declare that they have no competing interests.

\section{Authors' contributions}

JHC, GKS, SHK, RK, TA, Al and AGK contributed to the writing of the manuscript. All authors reviewed and approved the final version of the manuscript.

\section{Author details}

'Department of Hospital Medicine, Cleveland Clinic, OH, 9500 Euclid Avenue, M2-Annex, Cleveland, OH 44195, USA. ²Department of Internal Medicine, College of Medicine, University of Illinois at Urbana-Champaign, Champaign, IL, USA. ${ }^{3}$ Department of Nursing, Dankook University, Cheonan, Republic of Korea. ${ }^{4}$ Departments of Hospital Medicine and Outcomes Research Anesthesiology, Cleveland Clinic, Cleveland, OH, USA. ${ }^{5}$ Department of Cardiology, College of Medicine, University of Illinois at Urbana-Champaign, Champaign, IL, USA.

Received: 8 March 2014 Accepted: 1 May 2014

Published: 6 May 2014

\section{References}

1. Silverstein MD, Heit JA, Mohr DN, Petterson TM, O'Fallon WM, Melton $L J$ 3rd: Trends in the incidence of deep vein thrombosis and pulmonary embolism: a 25-year population-based study. Arch Intern Med 1998, 158(6):585-593.

2. Aujesky D, Roy PM, Verschuren F, Righini M, Osterwalder J, Egloff M, Renaud B, Verhamme P, Stone RA, Legall C, Sanchez O, Pugh NA, N'Gako A, Cornuz J, Hugli O, Beer HJ, Perrier A, Fine MJ, Yealy DM: Outpatient versus inpatient treatment for patients with acute pulmonary embolism: an international, open-label, randomised, non-inferiority trial. Lancet 2011, 378(9785):41-48 
3. Carson JL, Kelley MA, Duff A, Weg JG, Fulkerson WJ, Palevsky HI, Schwartz JS, Thompson BT, Popovich J Jr, Hobbins TE, Spera MA, Alavi A, Terrin ML: The clinical course of pulmonary embolism. N Engl J Med 1992, 326(19):1240-1245.

4. Sanchez O, Trinquart L, Colombet I, Durieux P, Huisman MV, Chatellier G, Meyer G: Prognostic value of right ventricular dysfunction in patients with haemodynamically stable pulmonary embolism: a systematic review. Eur Heart J 2008, 29(12):1569-1577.

5. Coutance G, Cauderlier E, Ehtisham J, Hamon M: The prognostic value of markers of right ventricular dysfunction in pulmonary embolism: a meta-analysis. Crit Care 2011, 15(2):R103.

6. Kearon C, Akl EA, Comerota AJ, Prandoni P, Bounameaux H, Goldhaber SZ, Nelson ME, Wells PS, Gould MK, Dentali F, Crowther M, Kahn SR: Antithrombotic therapy for VTE disease: Antithrombotic Therapy and Prevention of Thrombosis, 9th ed: American College of Chest Physicians Evidence-Based Clinical Practice Guidelines. Chest 2012, 141(2 Suppl):e419S-e494S.

7. Grifoni S, Olivotto I, Cecchini P, Pieralli F, Camaiti A, Santoro G, Conti A, Agnelli G, Berni G: Short-term clinical outcome of patients with acute pulmonary embolism, normal blood pressure, and echocardiographic right ventricular dysfunction. Circulation 2000, 101(24):2817-2822.

8. Yalamanchili K, Sukhija R, Aronow WS, Sinha N, Fleisher AG, Lehrman SG: Prevalence of increased cardiac troponin I levels in patients with and without acute pulmonary embolism and relation of increased cardiac troponin I levels with in-hospital mortality in patients with acute pulmonary embolism. Am J Cardiol 2004, 93(2):263-264.

9. Kucher N, Rossi E, De Rosa M, Goldhaber SZ: Prognostic role of echocardiography among patients with acute pulmonary embolism and a systolic arterial pressure of $90 \mathrm{~mm} \mathrm{Hg}$ or higher. Arch Intern Med 2005, 165(15):1777-1781.

10. Sukhija R, Aronow WS, Lee J, Kakar P, McClung JA, Levy JA, Belkin RN: Association of right ventricular dysfunction with in-hospital mortality in patients with acute pulmonary embolism and reduction in mortality in patients with right ventricular dysfunction by pulmonary embolectomy. Am J Cardiol 2005, 95(5):695-696.

11. Grifoni S, Vanni S, Magazzini S, Olivotto I, Conti A, Zanobetti M, Polidori G, Pieralli F, Peiman N, Becattini C, Agnelli G: Association of persistent right ventricular dysfunction at hospital discharge after acute pulmonary embolism with recurrent thromboembolic events. Arch Intern Med 2006, 166(19):2151-2156.

12. Pieralli F, Olivotto I, Vanni S, Conti A, Camaiti A, Targioni G, Grifoni S, Berni G: Usefulness of bedside testing for brain natriuretic peptide to identify right ventricular dysfunction and outcome in normotensive patients with acute pulmonary embolism. Am J Cardiol 2006, 97(9):1386-1390.

13. Jimenez D, Escobar C, Marti D, Diaz G, Vidal R, Taboada D, Ortega J, Moya $J$, Barrios V, Sueiro A: Prognostic value of transthoracic echocardiography in hemodynamically stable patients with acute symptomatic pulmonary embolism. Arch Bronconeumol 2007, 43(9):490-494.

14. Logeart D, Lecuyer L, Thabut G, Tabet JY, Tartiere JM, Chavelas C, Bonnin F, Stievenart JL, Solal AC: Biomarker-based strategy for screening right ventricular dysfunction in patients with non-massive pulmonary embolism. Intensive Care Med 2007, 33(2):286-292.

15. Palmieri V, Gallotta G, Rendina D, De Bonis S, Russo V, Postiglione A, Martino S, Di Minno MN, Celentano A: Troponin I and right ventricular dysfunction for risk assessment in patients with nonmassive pulmonary embolism in the Emergency Department in combination with clinically based risk score. Intern Emerg Med 2008, 3(2):131-138.

16. Gallotta G, Palmieri V, Piedimonte V, Rendina D, De Bonis S, Russo V, Celentano A, Di Minno MN, Postiglione A, Di Minno G: Increased troponin I predicts in-hospital occurrence of hemodynamic instability in patients with sub-massive or non-massive pulmonary embolism independent to clinical, echocardiographic and laboratory information. Int J Cardio/ 2008, 124(3):351-357.

17. Stein PD, Janjua M, Matta F, Pathak PK, Jaweesh F, Alrifai A, Chughtai HL: Prognosis based on creatine kinase isoenzyme MB, cardiac troponin I, and right ventricular size in stable patients with acute pulmonary embolism. Am J Cardiol 2011, 107(5):774-777.

18. Jimenez D, Aujesky D, Moores L, Gomez V, Marti D, Briongos S, Monreal M, Barrios V, Konstantinides S, Yusen RD: Combinations of prognostic tools for identification of high-risk normotensive patients with acute symptomatic pulmonary embolism. Thorax 2011, 66(1):75-81.
19. Rudski LG, Lai WW, Afilalo J, Hua L, Handschumacher MD, Chandrasekaran K, Solomon SD, Louie EK, Schiller NB: Guidelines for the echocardiographic assessment of the right heart in adults: a report from the American Society of Echocardiography endorsed by the European Association of Echocardiography, a registered branch of the European Society of Cardiology, and the Canadian Society of Echocardiography. J Am Soc Echocardiogr 2010, 23(7):685-713. quiz 786-688.

20. Becattini C, Vedovati MC, Agnelli G: Prognostic value of troponins in acute pulmonary embolism: a meta-analysis. Circulation 2007, 116(4):427-433.

21. Aujesky D, Obrosky DS, Stone RA, Auble TE, Perrier A, Cornuz J, Roy PM, Fine MJ: Derivation and validation of a prognostic model for pulmonary embolism. Am J Respir Crit Care Med 2005, 172(8):1041-1046.

22. Aujesky D, Roy PM, Le Manach CP, Verschuren F, Meyer G, Obrosky DS, Stone RA, Cornuz J, Fine MJ: Validation of a model to predict adverse outcomes in patients with pulmonary embolism. Eur Heart J 2006, 27(4):476-481.

23. Goldhaber SZ, Haire WD, Feldstein ML, Miller M, Toltzis R, Smith $J L$, da Taveira da Silva AM, Come PC, Lee RT, Parker JA, Mogtader A, McDonough TJ, Braunwald E: Alteplase versus heparin in acute pulmonary embolism: randomised trial assessing right-ventricular function and pulmonary perfusion. Lancet 1993, 341(8844):507-511.

24. Kline JA, Nordenholz KE, Courtney DM, Kabrhel C, Jones AE, Rondina MT, Diercks DB, Klinger JR, Hernandez J: Treatment of submassive pulmonary embolism with tenecteplase or placebo: cardiopulmonary outcomes at 3 months: multicenter double-blind, placebo-controlled randomized trial. J Thromb Haemost 2014, 12(4):459-468.

25. Meyer G, Vicaut E, Danays T, Agnelli G, Becattini C, Beyer-Westendorf J, Bluhmki E, Bouvaist H, Brenner B, Couturaud F, Dellas C, Empen K, Franca A, Galie N, Geibel A, Goldhaber SZ, Jimenez D, Kozak M, Kupatt C, Kucher N, Lang IM, Lankeit M, Meneveau N, Pacouret G, Palazzini M, Petris A, Pruszczyk P, Rugolotto M, Salvi A, Schellong S, et al: Fibrinolysis for patients with intermediate-risk pulmonary embolism. N Engl J Med 2014, 370(15):1402-1411.

\section{doi:10.1186/1471-2261-14-64}

Cite this article as: Cho et al:: Right ventricular dysfunction as an echocardiographic prognostic factor in hemodynamically stable patients with acute pulmonary embolism: a meta-analysis. BMC Cardiovascular Disorders 2014 14:64.

\section{Submit your next manuscript to BioMed Central and take full advantage of:}

- Convenient online submission

- Thorough peer review

- No space constraints or color figure charges

- Immediate publication on acceptance

- Inclusion in PubMed, CAS, Scopus and Google Scholar

- Research which is freely available for redistribution

Submit your manuscript at www.biomedcentral.com/submit
C Biomed Central 